\title{
Acute decrease of left ventricular mechanical dyssynchrony and improvement of contractile state and energy efficiency after left ventricular restoration
}

\author{
Jan J. Schreuder, MD, PhD \\ Alessandro Castiglioni, $\mathrm{MD}^{\mathrm{a}}$ \\ Francesco Maisano, MD ${ }^{\mathrm{a}}$ \\ Paul Steendijk, $\mathrm{PhD}^{\mathrm{b}}$ \\ Andrea Donelli, MS ${ }^{\mathrm{a}}$ \\ Jan Baan, $\mathrm{PhD}^{\mathrm{b}}$ \\ Ottavio Alfieri, MD
}

Objective: Surgical left ventricular restoration by means of endoventricular patch aneurysmectomy in patients with postinfarction aneurysm should result in acute improved left ventricular performance by decreasing mechanical dyssynchrony and increasing energy efficiency.

Methods: Nine patients with left ventricular postinfarction aneurysm were studied intraoperatively before and after ventricular restoration with a conductance volume catheter to analyze pressure-volume relationships, energy efficiency, and mechanical dyssynchrony. The end-systolic elastance was used as a load-independent index of contractile state. Left ventricular energy efficiency was calculated from stroke work and total pressure-volume area. Segmental volume changes perpendicular to the long axis were used to calculate mechanical dyssynchrony. Statistical analysis was performed with the paired $t$ test and least-squares linear regression.

Results: Endoventricular patch aneurysmectomy reduced end-diastolic volume by $37 \%(P<.001)$, with unchanged stroke volume. Systolic function improved, as derived from increased $+\mathrm{dP} / \mathrm{dt}_{\max }$, by $42 \%(P<.03)$, peak ejection rate by $28 \%(P$ $<.02)$, and ejection fraction by $16 \%(P<.0002)$. Early diastolic function improved, as shown by reduction of $-\mathrm{dP}^{\mathrm{d}} \mathrm{dt}_{\max }$ by $34 \%(P<.006)$ and shortened $\tau$ by $30 \%(P<.001)$. Left ventricular end-systolic elastance increased from $1.2 \pm 0.6$ to $2.2 \pm 1 \mathrm{~mm} \mathrm{Hg} / \mathrm{mL}(P<.001)$. Left ventricular energy efficiency increased by $36 \%$ $(P<.002)$. Left ventricular mechanical dyssynchrony decreased during systole by

From the Department of Cardiac Surgery, San Raffaele University Hospital, Milan, Italy, and the Department of Cardiology, ${ }^{\mathrm{b}}$ Leiden University Medical Center, Leiden, The Netherlands.

Received for publication July 4, 2003; revisions received Feb 22, 2004; accepted for publication March 30, 2004.

Address for reprints: Jan J. Schreuder, MD, $\mathrm{PhD}$, Department of Cardiac Surgery, San Raffaele University Hospital, Via Olgettina 60,20132 Milano, Italy (E-mail: schreuder@ libero.it).

J Thorac Cardiovasc Surg 2005;129:138-45 $0022-5223 / \$ 30.00$

Copyright $\odot 2005$ by The American Association for Thoracic Surgery

doi:10.1016/j.jtcvs.2004.03.057 $33 \%(P<.001)$ and during diastole by $20 \%(P<.005)$.

Conclusions: Left ventricular restoration induced acute improvements in contractile state, energy efficiency, and relaxation, together with a decrease in left ventricular mechanical dyssynchrony.

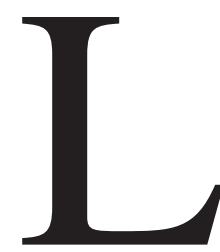

eft ventricular (LV) postinfarction aneurysm is characterized by akinetic or dyskinetic LV wall motions, or both. Ventricular nonuniformity of contraction and relaxation reduces mechanical efficiency of ventricular filling and ejection and contributes to diastolic and systolic dysfunction. ${ }^{1,2}$ Consequently, postinfarction LV aneurysm is associated with reduced ejection fraction (EF) caused by LV dilatation to maintain stroke volume (SV), with impaired LV relaxation and decreased energy efficiency.

LV aneurysm resection according to a linear suture technique induced increased LV ejection fraction (LVEF), but only slight hemodynamic improvements in pa- 
tients with congestive heart failure were observed. ${ }^{3-5}$ Endoventricular patch aneurysmectomy was introduced to improve LV geometry, showing better outcome compared with that seen with the linear suture technique. ${ }^{6-9}$ The efficacy and safety of a similar procedure was demonstrated in a multicenter study consisting of 439 patients with anterior myocardial infarction. ${ }^{10}$

Reductions in regional LV wall-motion abnormalities after patch aneurysmectomy have been demonstrated. ${ }^{11}$ In previous studies we observed that LV volume reduction by means of cardiomyoplasty or partial ventriculectomy in patients with dilated cardiomyopathy decreased LV mechanical dyssynchrony by decreasing LV wall stress. ${ }^{12,13}$ We hypothesized that LV volume decrease through the excision of the akinetic area, the dyskinetic area, or both, and the geometric remodeling by means of LV restoration should result in an acute decrease in mechanical dyssynchrony and, consequently, immediate improvement of LV energy efficiency and performance. Therefore we analyzed the intraoperative effects of LV restoration by means of endoventricular patch aneurysmectomy on LV performance, on LV energy efficiency, and on mechanical dyssynchrony from the pressure-volume $(\mathrm{P}-\mathrm{V})$ plane by using the conductance catheter technique. ${ }^{12-18}$

\section{Methods \\ Study Group}

Nine consecutive patients with LV postinfarction aneurysm scheduled to undergo endoventricular patch aneurysmectomy were studied immediately before and after cardiopulmonary bypass (Table 1). All patients had EFs of less than $35 \%$ and were in sinus rhythm. Seven patients concomitantly underwent coronary artery bypass grafting $(\mathrm{CABG})$. Patients were treated with prophylactic intraaortic balloon counterpulsation from anesthetic induction until 24 hours after the operation.

The study was approved by the medical ethics committee. All patients provided written informed consent.

\section{Instrumentation}

All patients received high-dose opioid anesthesia. A thermodilution catheter was placed in the pulmonary artery. An intra-aortic balloon (8F, Narrowflex; Arrow International, Reading, Pa) was introduced through a femoral artery under transesophageal echocardiographic control. A combined micromanometer pressure-conductance catheter (7F, CD Leycom, Zoetermeer, The Netherlands) was inserted through a pulmonary vein into the left ventricle for measurement of pressure and volume. The feasibility of the conductance catheter method during cardiac surgery has been shown in previous studies. ${ }^{13,15}$ Correct positioning of the conductance catheter was verified by means of transesophageal echocardiography and by means of inspection of the segmental conductance signals. The conductance catheter coupled to a cardiac function analyzer (Leycom CFL512, CD Leycom) measures LV segmental and total volumes by using a dual-field excitation mode. ${ }^{12-16}$

\section{TABLE 1. Patient characteristics}

\begin{tabular}{lcccc}
\hline $\begin{array}{l}\text { Patient } \\
\text { no. }\end{array}$ & Age/sex & $\begin{array}{c}\text { Associated } \\
\text { operation }\end{array}$ & NYHA & EF (\%) \\
\hline 1 & $61 / \mathrm{M}$ & CABG & II & 32 \\
2 & $70 / \mathrm{F}$ & CABG & II & 35 \\
3 & $64 / \mathrm{M}$ & & III & 19 \\
4 & $61 / \mathrm{M}$ & CABG & III & 15 \\
5 & $62 / \mathrm{M}$ & & III & 15 \\
6 & 73/M & CABG & III & 25 \\
7 & $66 / \mathrm{F}$ & CABG & III & 22 \\
8 & $65 / \mathrm{M}$ & CABG & II & 33 \\
9 & 57/M & CABG & III & 16
\end{tabular}

$\overline{N Y H A}$, New York Heart Association; $E F$, ejection fraction; $C A B G$, coronary artery bypass grafting.

Time-varying segmental conductances reflect time-varying segmental $\mathrm{LV}$ volumes. ${ }^{17}$

The parallel conductance offset term was determined by means of injection of $10 \mathrm{~mL}$ of hypertonic saline solution (6\%) into the pulmonary artery. ${ }^{14}$ Effective conductance SV was defined as the difference between conductance volumes at the times of $+\mathrm{dP} /$ $\mathrm{dt}_{\max }$ and $-\mathrm{dP} \mathrm{dt}_{\max }$, which largely eliminates the contribution of possible regurgitant flows. Cardiac output was determined by performing 4 thermodilution measurements at equidistant moments in the ventilatory cycle. ${ }^{15}$ Absolute LV volumes were calculated by matching effective conductance SV with simultaneously measured thermodilution SV and by subtracting parallel conductance from total conductance volume. Both the thermodilution and hypertonic saline methods are indicator dilution methods and therefore independent of anticipated geometric changes, as will be caused by means of endoventricular patch aneurysmectomy.

\section{Surgical Procedure}

The surgical technique used was the endoventricular patch aneurysmectomy, as described by Dor and colleagues. ${ }^{7}$ After initiation of cardiopulmonary bypass with moderate hypothermia, the aorta was crossclamped, and cardiac arrest was obtained by infusion of antegrade and retrograde cold blood cardioplegic solution. Coronary revascularization was performed first. Subsequently, a linear incision was made through the fibrotic area, and a part of the endocardial scar was resected. At the demarcation line between normal muscle and fibrous tissue, a Teflon double velour patch was anchored inside the ventricle with a running polypropylene suture. The remnants of the aneurysmatic wall were sutured over the patch for hemostasis.

\section{Mechanical Ventricular Dyssynchrony}

Ventricular dyssynchrony assessment from segmental LV volume measurements has been previously described for cineangiography and the conductance catheter. ${ }^{2,13,18}$ Time-varying segmental volume, as measured with the conductance catheter, has been validated by means of cineangiography. ${ }^{17}$ Mechanical ventricular dyssynchrony, as measured with the conductance catheter, has been validated by means of tissue Doppler echocardiography. ${ }^{18}$ The conductance catheter measures volume segments located perpen- 

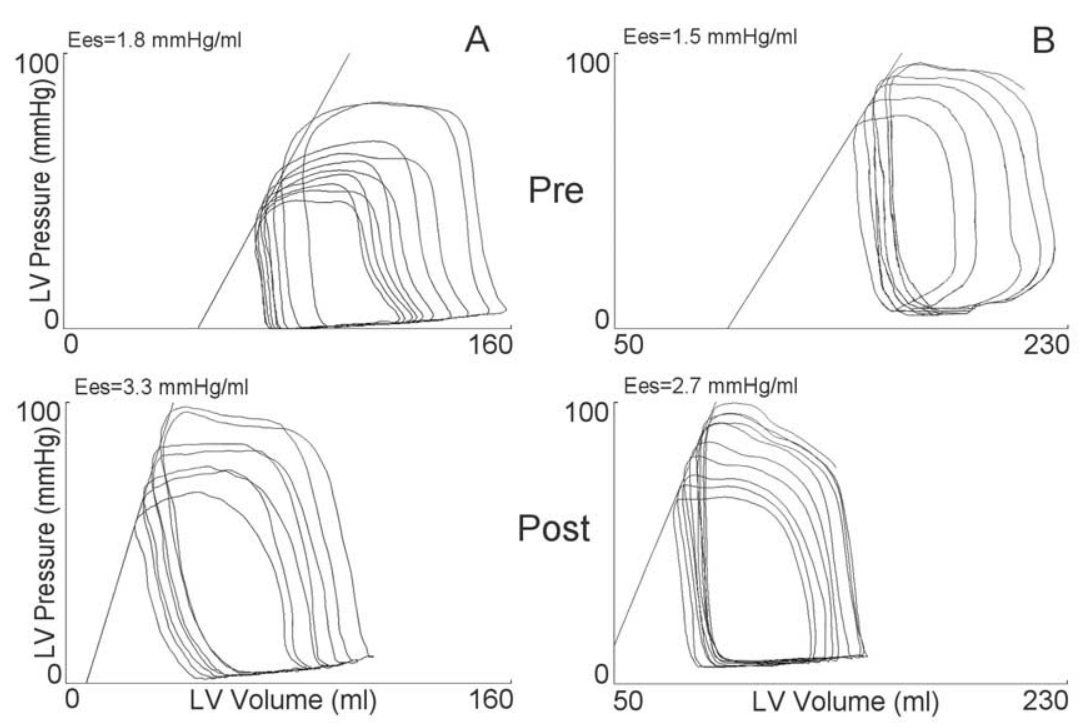

Figure 1. LV P-V relationships during caval vein occlusion in 2 patients $(A$ and $B)$ before and after endoventricular patch aneurysmectomy. The P-V loops shifted to the left after aneurysmectomy, with concomitant increases in Ees.

dicular to the long heart axis. A volume segment was defined as dyssynchronous when the volume change in that segment was in the opposite direction (dyskinetic) or showed no change (akinetic) compared with total LV volume change. Segmental dyssynchrony was quantified by percentage time, and a segment was dyssynchronous in relationship to total volume change; total dyssynchrony was the average of segmental dyssynchrony in all segments. ${ }^{2,13,18}$ Systolic dyssynchrony was calculated from R-wave to $-\mathrm{dP} / \mathrm{dt}_{\max }$ and diastolic dyssynchrony from $-\mathrm{dP} / \mathrm{dt}_{\max }$ to $\mathrm{R}-$ wave. The systolic phase was subdivided in early systole, from $\mathrm{R}$-wave to $+\mathrm{dP}^{\mathrm{dt}} \mathrm{d}_{\max }$ and late systole from $+\mathrm{dP} / \mathrm{dt}_{\max }$ to endsystolic volume (ESV). The diastolic phase was subdivided in early diastole from ESV to peak filling rate and late diastole from peak filling rate to $\mathrm{R}$-wave.

\section{Data Acquisition and Analysis}

Echocardiography, LV pressure, and LV volume signals were digitized at a sampling rate of $250 \mathrm{~Hz}$ and stored on hard disk for subsequent analysis. In addition to volumetric variables, dyssynchrony, pressures, and the peak first derivatives, the following variables were calculated: $\tau$, the time constant of LV pressure relaxation, which was defined as the time required from the LV pressure at peak $-\mathrm{dP} / \mathrm{dt}$ to be reduced by half ${ }^{19}$, and peak ejection rate, which was calculated as maximal $-\mathrm{dV} / \mathrm{dt}$. Effective LVEF was calculated from the thermodilution-derived SV and LV enddiastolic volume (EDV), as measured with the conductance catheter. The load-independent indices of contractile state, end-systolic elastance (Ees), preload recruitable stroke work (PRSW), and the relationship of $+\mathrm{dP} / \mathrm{dt}_{\text {max }}$ versus EDV were determined from P-V loops acquired during preload reduction procedures. Stroke work divided by total $\mathrm{P}-\mathrm{V}$ area was used to determine the LV energy efficiency, according to the method of Suga and colleagues. ${ }^{20}$

\section{Measurement Protocol}

Hemodynamic measurements were obtained at two stages: immediately before and 15 minutes after cardiopulmonary bypass. We calibrated the conductance catheter at each stage of the procedure by determining parallel conductance and by means of thermodilution SV. Steady state P-V loops were acquired for 15 seconds during suspended ventilation. Preload reduction was performed by means of transient occlusion of the inferior vena cava during 15 seconds to assess Ees, PRSW, $+\mathrm{dP}_{\mathrm{dt}} \mathrm{max}_{\text {mat }}-\mathrm{EDV}$, and LV energy efficiency during suspended ventilation. Data acquisitions before and after aneurysmectomy were performed with suspended intraaortic balloon pump, but in patients with the lowest EF (patients 3, 4, 5, and 9; Table 1), data acquisition was performed with an intra-aortic balloon pump at a 1:1 assist ratio.

\section{Statistics}

All values are reported as means \pm SD. Differences between prebypass and postbypass hemodynamic data were assessed by using paired $t$ tests. Statistical relationships between variables were tested by using least-squares linear regression.

\section{Results}

\section{Hemodynamics}

Characteristics of all patients are presented in Table 1. Identical doses $\left(<5 \mu \mathrm{g} \cdot \mathrm{kg}^{-1} \cdot \mathrm{min}^{-1}\right)$ of dobutamine were used before and after cardiopulmonary bypass in patients with the lowest EF (patients 3, 4, 5, and 9).

Figure 1 shows typical P-V relationships of 2 patients acquired during preload reduction before and after patch aneurysmectomy, indicating an increase in Ees in both patients, with concomitant leftward shifts of the P-V loops. 
TABLE 2. Hemodynamic data $(n=9)$

\begin{tabular}{|c|c|c|c|}
\hline & \multicolumn{2}{|c|}{ Aneurysmectomy } & \multirow[b]{2}{*}{$P$ value } \\
\hline & Before & After & \\
\hline $\mathrm{HR}\left(\min ^{-1}\right)$ & $76 \pm 16$ & $99 \pm 21$ & $<.01$ \\
\hline $\mathrm{Cl}\left(\mathrm{L} \cdot \mathrm{min}^{-1} \cdot \mathrm{m}^{-2}\right)$ & $1.96 \pm 0.5$ & $2.62 \pm 0.5$ & $<.01$ \\
\hline SV $(\mathrm{mL})$ & $46 \pm 12$ & $48 \pm 12$ & \\
\hline EDP (mm Hg) & $9.4 \pm 3$ & $13.8 \pm 3$ & $<.03$ \\
\hline $\mathrm{ESP}(\mathrm{mm} \mathrm{Hg})$ & $74 \pm 13$ & $79 \pm 18$ & \\
\hline $\operatorname{EDV}\left(\mathrm{mL} / \mathrm{m}^{2}\right)$ & $123 \pm 35$ & $78 \pm 18$ & $<.001$ \\
\hline $\mathrm{ESV}\left(\mathrm{mL} / \mathrm{m}^{2}\right)$ & $92 \pm 33$ & $45 \pm 19$ & $<.0001$ \\
\hline$+\mathrm{dP} / \mathrm{dt}_{\max }(\mathrm{mm} \mathrm{Hg} / \mathrm{s})$ & $787 \pm 276$ & $1116 \pm 171$ & $<.03$ \\
\hline PER $(\mathrm{mL} / \mathrm{s})$ & $452 \pm 141$ & $578 \pm 190$ & $<.02$ \\
\hline $\mathrm{EF}(\%)$ & $23.6 \pm 8$ & $39.4 \pm 13$ & $<.0002$ \\
\hline$-\mathrm{dP} \mathrm{dt}_{\max }(\mathrm{mm} \mathrm{Hg} / \mathrm{s})$ & $-601 \pm 145$ & $-803 \pm 72$ & $<.006$ \\
\hline$\tau(\mathrm{ms})$ & $59 \pm 7$ & $41.3 \pm 9.2$ & $<.001$ \\
\hline Ees $(\mathrm{mm} \mathrm{Hg} / \mathrm{mL})$ & $1.2 \pm 0.6$ & $2.2 \pm 1.0$ & $<.001$ \\
\hline$+\mathrm{dP} / \mathrm{dt}_{\max }-\operatorname{EDV}\left(\mathrm{mm} \mathrm{Hg} \cdot \mathrm{s}^{-1} \cdot \mathrm{mL}^{-1}\right)$ & $6.9 \pm 4.5$ & $22 \pm 14$ & $<.01$ \\
\hline PRSW (mm Hg) & $42 \pm 22$ & $72 \pm 22$ & $<.01$ \\
\hline SW/PVA (\%) & $38.6 \pm 16$ & $52.5 \pm 16$ & $<.002$ \\
\hline
\end{tabular}

$H R$, Heart rate; $C l$, cardiac index; $S V$, stroke volume; $E D P$, end-diastolic pressure; $E S P$, end-systolic pressure; $E D V$, end-diastolic volume; $E S V$, end-systolic volume; PER, peak ejection rate; EF, ejection fraction; Ees, end-systolic elastance; PRSW, preload recruitable stroke work; SW, stroke work; PVA, pressure-volume area.

Table 2 provides data on all 9 patients measured before and after patch aneurysmectomy. LV end-systolic pressure did not change significantly, whereas LV end-diastolic pressure increased by a mean of $4 \mathrm{~mm} \mathrm{Hg}(P<.03)$. LVEDV and LVESV decreased by a mean of $37 \%(P<.001)$ and $51 \%$ $(P<.0001)$, respectively. Cardiac index and heart rate $(\mathrm{HR})$ increased by $34 \%(P<.01)$ and $30 \%(P<.01)$, respectively, whereas SV remained constant. The increase in HR correlated with a decrease in LVEDV $(r=-0.679 ; P=$ .044).

Systolic function improved as indicated by a mean increase in $+\mathrm{dP} / \mathrm{dt}_{\max }$ of $42 \%(P<.03)$, peak ejection rate increased by $28 \%(P<.02)$, and net $\mathrm{EF}$ increased by $16 \%$ $(P<.0002)$. Early diastolic function improved as indicated by a mean $34 \%$ decrease in $-\mathrm{dP}^{2} \mathrm{dt}_{\max }(P<.006)$ and a mean $30 \%$ decrease in $\tau(P<.001)$. The contractile state indices Ees and $+\mathrm{dP}^{\mathrm{dt}} \mathrm{t}_{\max }$ versus EDV and PRSW markedly improved, on average, by $83 \%(P<.001), 71 \%(P<$ $.01)$, and $318 \%(P<.01)$, respectively. The LV energy efficiency, determined by stroke work divided by the P-V area, improved by a mean relative increase of $36 \%(P<$ $.002)$.

\section{Mechanical Dyssynchrony}

Figure 2 presents typical LV segmental and total volume recordings during 4 consecutive heart cycles of 2 patients before and after patch aneurysmectomy. Before aneurysmectomy, the LV apical volume segments show the most pronounced dyskinetic and akinetic characteristics. Obvious decreases in apical segmental dyssynchrony are present after patch aneurysmectomy. Table 3 shows systolic and diastolic dyssynchrony data of all patients measured before and after the procedure. Preoperatively, the 3 apical segmental volumes, representing dyskinetic and akinetic contributions of the postinfarction aneurysms (Figure 2), were significantly more dyssynchronous during systole and diastole compared with the basal segments $(P<.001)$. After aneurysmectomy, LV total systolic dyssynchrony was decreased relatively by a mean of $33 \%(P<.001)$, and total diastolic dyssynchrony was decreased relatively by a mean of 20\% $(P<.005)$, primarily because of decreases in dyssynchrony of the 3 apical segments during systole and diastole (Table 3). Postoperatively, the 2 apical segments were still significantly $(P<.005)$ more dyssynchronous compared with the 2 basal segments. Early systolic dyssynchrony, from R-wave to peak $+\mathrm{dP} / \mathrm{dt}_{\max }$, did not change significantly, whereas late systolic dyssynchrony, from peak $+\mathrm{dP} / \mathrm{dt}_{\text {max }}$ to LVESV, decreased relatively by a mean of $54 \%(P<.0005$, Table 4$)$. Early LV diastolic dyssynchrony, from LVESV to peak filling rate, decreased relatively by a mean of $23 \%(P<.005)$, whereas late diastolic dyssynchrony, from peak filling rate to R-wave, did not change significantly (Table 4).

Comparing preoperative and postoperative values revealed that systolic dyssynchrony correlated with Ees $(P=$ .00066; Figure 3, $A)$ and with $\tau(P=.00006$; Figure 3, $B)$ and LV energy efficiency $(P=.001$; Figure $3, C)$. The net increase in Ees after endoventricular patch aneurysmectomy correlated significantly with a decrease in diastolic dyssynchrony $(P=.0094$; Figure $3, D)$. 

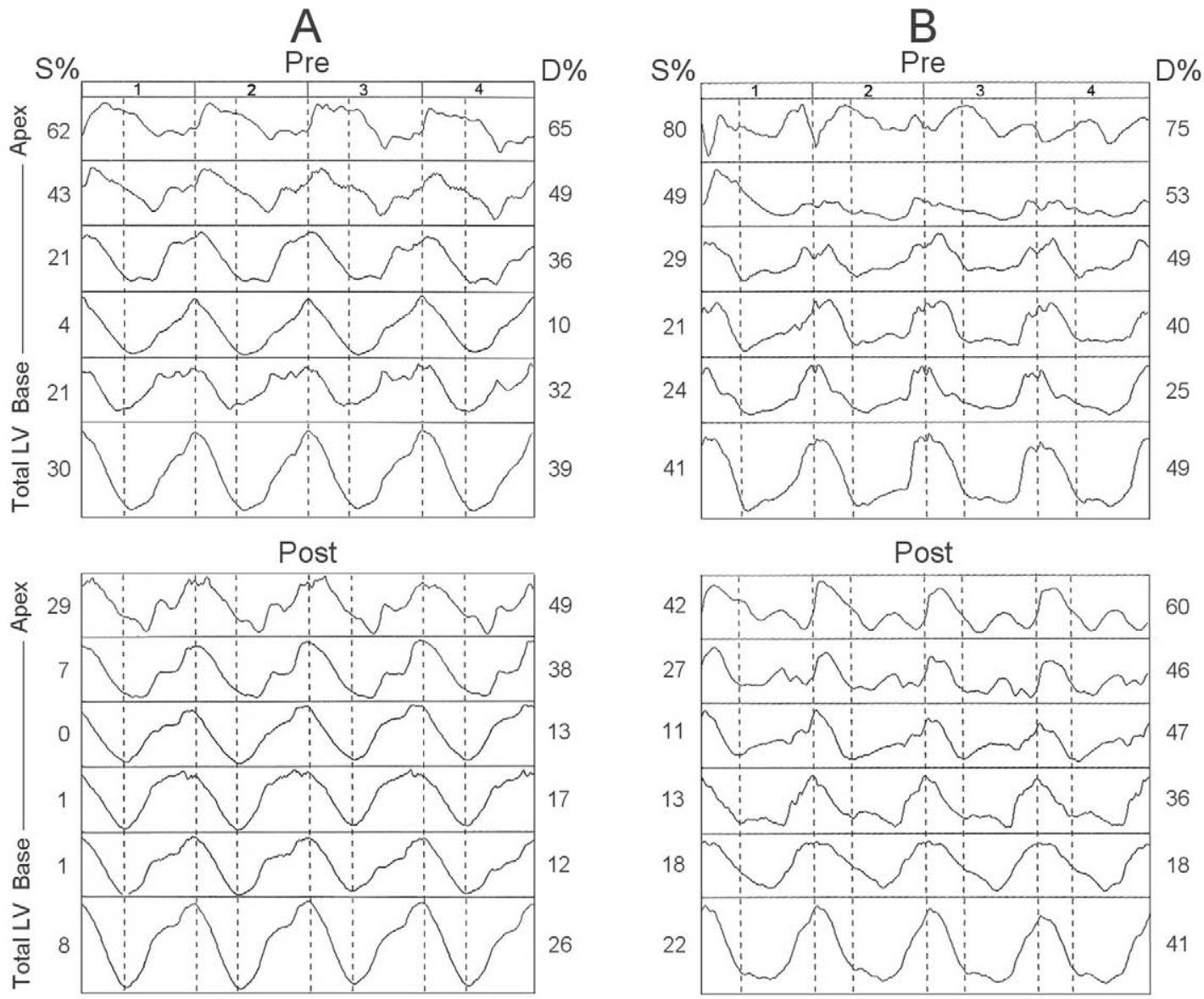

Figure 2. Tracings of $L V$ volume segments during 4 consecutive heart beats of 2 patients $(A$ and $B)$ before and after endoventricular patch aneurysmectomy. Dotted lines, Start or end of the LV ejection phase. LV segmental dyssynchrony and total LV dyssynchrony values along the long axis during systole (S\%) and during diastole (D\%) are shown. LV restoration induced a marked decrease in dyssynchrony.

TABLE 3. Left ventricular dyssynchrony I $(n=9)$

\begin{tabular}{|c|c|c|c|c|}
\hline \multirow[b]{3}{*}{ Segments } & \multicolumn{4}{|c|}{ Aneurysmectomy } \\
\hline & \multicolumn{2}{|c|}{ Before } & \multicolumn{2}{|c|}{ After } \\
\hline & Systole & Diastole & Systole & Diastole \\
\hline Apical 1 & $64 \pm 15$ & $66 \pm 14$ & $46 \pm 10^{*}$ & $51 \pm 8 \dagger$ \\
\hline Apical 2 & $46 \pm 9$ & $49 \pm 15$ & $27 \pm 11 \dagger$ & $38 \pm 9^{*}$ \\
\hline Mid & $28 \pm 7$ & $39 \pm 8$ & $16 \pm 10 \ddagger$ & $26 \pm 14 \dagger$ \\
\hline Base 2 & $18 \pm 7$ & $23 \pm 10$ & $16 \pm 5$ & $23 \pm 6$ \\
\hline Base 1 & $23 \pm 10$ & $25 \pm 7$ & $17 \pm 7$ & $25 \pm 11$ \\
\hline Total & $36 \pm 4$ & $40 \pm 7$ & $24 \pm 7 \ddagger$ & $32 \pm 6 \dagger$ \\
\hline
\end{tabular}

* $P<.05$

$\dagger P<.01$

$\ddagger P<.001$

\section{Discussion}

This study shows significant acute beneficial effects of LV restoration by means of endoventricular patch aneurysmectomy in patients with LV postinfarction aneurysm. LV
TABLE 4. Left ventricular dyssynchrony II $(n=9)$

\begin{tabular}{llll}
\hline & \multicolumn{2}{c}{ Aneurysmectomy } & \\
\cline { 2 - 3 } & \multicolumn{1}{c}{ Before } & After & P value \\
\hline Early systole & $43 \pm 7$ & $36 \pm 10$ & .08 \\
Late systole & $28 \pm 7$ & $13 \pm 8.5$ & .0004 \\
Early diastole & $44 \pm 6$ & $34 \pm 7$ & .004 \\
Late diastole & $31 \pm 10.5$ & $29 \pm 8$ & .66
\end{tabular}

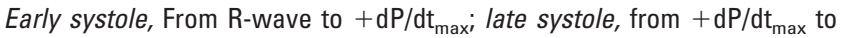
end-systolic volume; early diastole, from end-systolic volume to peak filling rate; late diastole, from peak filling rate to $\mathrm{R}$ wave.

mechanical dyssynchrony was markedly reduced and LV energy efficiency was markedly increased by the LV volume reduction and surgical geometric remodeling. The load-independent contractility indices Ees, PRSW, and $+\mathrm{dP} / \mathrm{dt}_{\max }-\mathrm{EDV}$ acutely improved after $\mathrm{LV}$ restoration. The increase in Ees after patch LV restoration correlated in- 
versely with LV diastolic dyssynchrony. Early diastolic function, as shown by the $\mathrm{LV}$ relaxation indices $-\mathrm{dP} / \mathrm{dt}_{\max }$ and $\tau$, improved.

\section{Hemodynamics}

The observed acute decrease in LVEDV by $37 \%$ and increase in EF from $24 \%$ to $39 \%$ on the average immediately after endoventricular patch aneurysmectomy is consistent with previous reported findings. ${ }^{11,21}$ The acute decreases in LVEDV and ESV after aneurysmectomy are also comparable with those observed acutely after partial ventriculectomy and long term after cardiomyoplasty. ${ }^{12,13}$

The $\mathrm{LV}$ relaxation indices $-\mathrm{dP} / \mathrm{dt}_{\max }$ and $\tau$ are generally decreased and prolonged, respectively, in congestive heart failure and in LV aneurysm, which is indicative for LV mechanical dyssynchrony in early diastole. ${ }^{2,12,13,22}$ In the present patient group these variables also were markedly abnormal, whereas $\tau$ correlated strongly with systolic dyssynchrony (Figure 3, B). After patch aneurysmectomy, $-\mathrm{dP} / \mathrm{dt}_{\max }$ was lower and $\tau$ was markedly shorter, indicating an improvement in LV relaxation of the compromised early diastole.

Mean SV did not change significantly, whereas cardiac index increased significantly because of the significant increase in HR. Heart increase, which correlated with the decrease in LVEDV, was unlikely to be related to inotropic agents because they were administered in equal low dosages before and after cardiopulmonary bypass in 4 patients.

End-diastolic compliance decreased immediately after LV restoration. Previously, we demonstrated a considerable increase in the slope of the diastolic P-V relationship after cardiopulmonary bypass in patients undergoing $\mathrm{CABG}$, indicating increases in passive ventricular stiffness. ${ }^{15}$ Moreover, immediately after aneurysmectomy, LV end-diastolic pressure might have increased, possibly because of edema around suture lines.

\section{Mechanical Dyssynchrony and Energy Efficiency}

Before endoventricular patch aneurysmectomy, marked LV dyssynchronic segmental volume changes were observed throughout the cardiac cycle, indicating diastolic and systolic dyskinetic and akinetic wall motion. They were converted into more synchronous wall-motion patterns after patch aneurysmectomy (Figure 2 and Tables 3 and 4). Nonuniformity of wall motion reduces the mechanical efficiency of ventricular ejection by inducing a premature onset and impairment of LV relaxation. ${ }^{1,2}$ The aspect of segmental volume dyssynchrony along the long heart axis, most pronounced in the apical and midventricular zones, reveals the ineffective mechanical cardiac work, which improved together with the LV energy efficiency in all patients after LV restoration. In all patients, 5 volume segments were measured. However, in case of very large ventricles, the
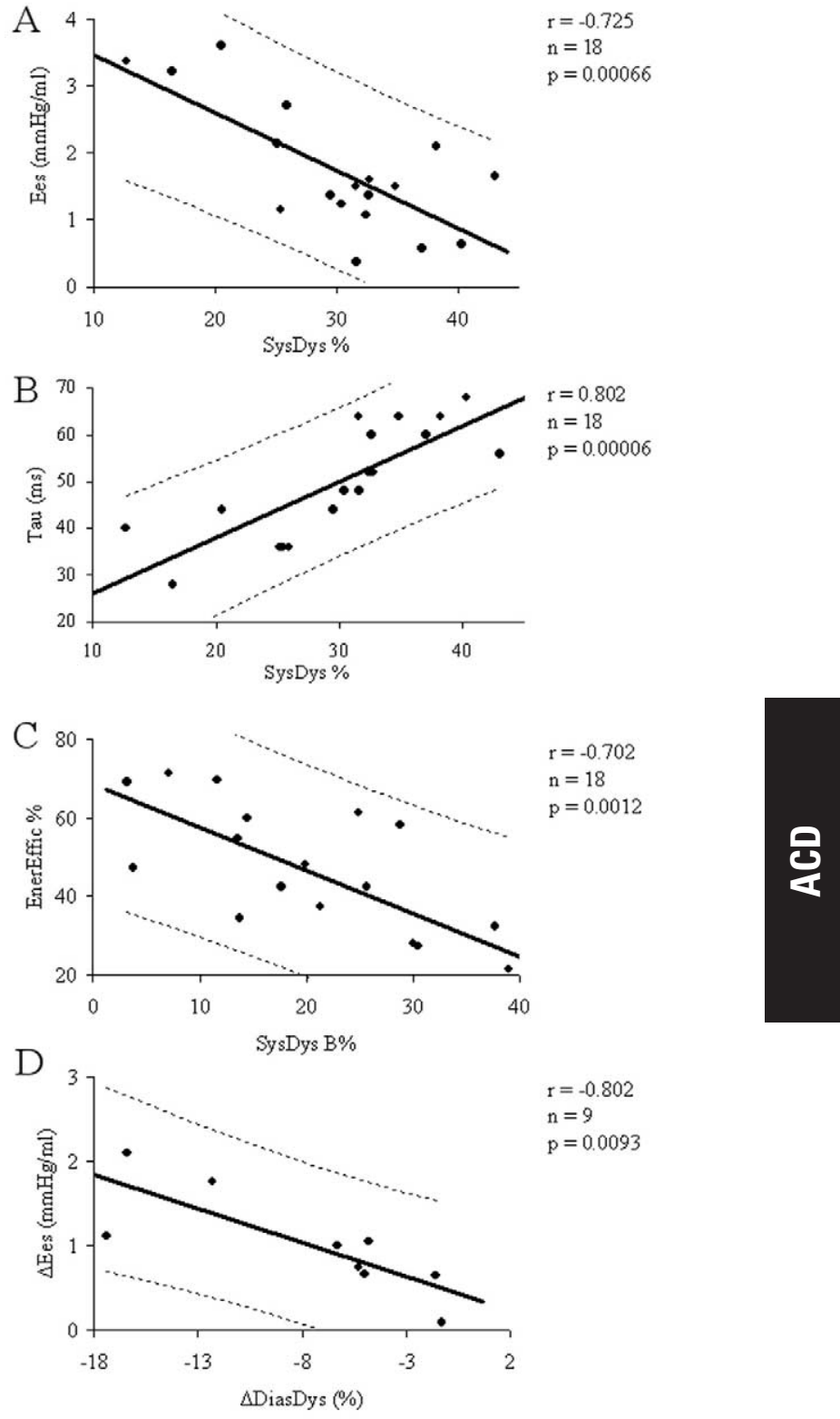

Figure 3. Regression diagrams showing Ees versus LV systolic dyssynchrony (SysDys, A); $\tau$ versus LV systolic dyssynchrony (B); LV energy efficiency (EnerEffic; SW/PVA) versus LV systolic dyssynchrony (C); and changes in Ees versus changes in LV diastolic dyssynchrony ( $\Delta$ DiaDys, D). Dotted lines represent $95 \%$ prediction limits.

electrode distances of the basal segments were doubled to ensure a maximal view of the left ventricle. Simultaneously, the relative contributions of those double segments were doubled for total dyssynchrony calculations. Once the apex was removed, the planes corresponded with the new apical planes, whereas the basal planes were still in the same position, although not always doubled. The calculated av- 
eraged dyssynchrony of the left ventricle therefore represents a relative dyssynchrony index of the whole ventricle.

Although reduced, variable degrees of dyssynchrony remained present in the 2 apical segments after the aneurysmectomy, indicating that the geometric reconstruction was only in part successful (Figure 2, B). Di Donato and colleagues ${ }^{11}$ demonstrated improvements of regional wall motion at the posterobasal, inferior, and anterobasal zones after patch aneurysmectomy. Wall stress decreases caused by LV volume reduction have an LV synchronizing effect, as was demonstrated after partial left ventriculectomy and cardiomyoplasty. ${ }^{12,13}$ In the present study a similar reduction in wall stress occurs as LV volume is reduced, whereas systolic pressure and wall thickness remain unaffected. The synchronizing effect of endoventricular patch aneurysmectomy can therefore be ascribed to excision of the akinetic area, the dyskinetic area, or both; surgical geometric remodeling; and a decrease in wall stress caused by LV volume decrease. LV mechanical dyssynchrony (mechanical inefficiency) correlated markedly inversely with LV energy efficiency and with increase in Ees (Figure 3, $C$ and $D$ ).

The conductance catheter technique allows an analysis of dyskinesia and akinesia at high-time resolution, and as a consequence, dyskinetic areas will be detected more frequently compared with techniques with lower temporal resolution, such as cine-angiography. Previous studies suggested that aneurysmectomy should be applied on dyskinetic but not akinetic areas. However, Di Donato and coworkers $^{23}$ demonstrated that surgical outcome of $\mathrm{LV}$ restoration is related to the extent of LV dyssynchrony and not to dyskinesia or akinesia.

\section{Contractile State}

The load-independent contractility indices Ees, PRSW, and $+\mathrm{dP} / \mathrm{dt}_{\text {max }}$ versus EDV acutely improved after LV restoration. Similar findings were observed in an animal study assessing acute effects of aneurysm plication. ${ }^{24}$ However, the study mentioned a decreased Frank-Starling relationship (SV vs sarcomere length), whereas this relationship was improved in a clinical endoventricular patch aneurysmectomy study. ${ }^{11}$ Both studies used LVEDV as a substitute for sarcomere length. But the decrease in LV dyssynchrony and the LV volume reduction make an analysis in terms of the Frank-Starling relationship questionable because mean sarcomere length before and after aneurysmectomy are unknown. The Ees, however, is independent of the preload reduction induced by the surgical LV reduction and therefore suitable to apply in aneurysmectomy.

\section{Limitations of the Study}

Although 7 patients had additional CABG, some major effects, like the change in uniformity of contraction and relaxation and the significant increase in Ees, can be pri- marily attributed to $\mathrm{LV}$ restoration because in a previous study we could not demonstrate a significant acute change in Ees after CABG. ${ }^{15}$ The number of patients in this study is too small to perform a subgroup analysis (with or without $\mathrm{CABG}$ ), and therefore the independent effects of CABG on dyssynchrony require further study.

The study was performed in patients after achievement of anesthesia, and some patients received small dosages of dobutamine before and after aneurysmectomy. Moreover, in all patients intra-aortic balloon counterpulsation was applied before and after the procedure. Therefore the absolute values of all measured variables might have been different when measured in the awake state and without additional therapies.

The increased HR after CPB might have contributed to increased Ees after LV restoration. However, Ees is relatively insensitive to changes in HR, as was demonstrated in animal studies; only changes from very low HR to the midrange resulted in significant changes in Ees. ${ }^{25,26} \mathrm{HR}$ inversely correlated with LV volume decrease, whereas no significant correlation between HR and Ees was observed. Moreover, equal dosages of inotropic agents were used before and after LV restoration.

\section{Conclusions}

The reduction in LV cavity volume after endoventricular patch aneurysmectomy resulted in a significant immediate improvement of the contractile state, as assessed by Ees, PRSW, and $+\mathrm{dP}^{\mathrm{d}} \mathrm{dt}_{\max }$ versus EDV.

LV mechanical dyssynchrony decreased, and LV energy efficiency increased significantly after LV restoration, probably because of geometric improvements produced by the surgical procedure and a decrease in LV volume, decreasing wall stress. Increase in Ees correlated significantly with a decrease in LV diastolic dyssynchrony. The applied conductance catheter technique allows intraoperative evaluation of the LV mechanical and energy efficiency, which might be of value for long-term outcome of LV restoration.

We thank Dr Hein Putter, PhD, for the statistical review.

\section{References}

1. Brutsaert DL. Nonuniformity: a physiologic modulator of contraction and relaxation of the normal heart. J Am Coll Cardiol. 1987;9:341-8.

2. Aoyagi T, Pouleur H, Van Eyll C, Rousseau MF, Mirsky I. Wall motion asynchrony is a major determinant of impaired left ventricular filling in patients with healed myocardial infarction. Am J Cardiol. 1993;72:268-72.

3. Sesto M, Schwartz F, Thiedemann K, Flameng W, Schlepper M. Failure of aneurysmectomy to improve left ventricular function. $\mathrm{Br}$ Heart J. 1979;41:79-88.

4. Muhlberger V, Knapp E, Hopferweiser T, Scharfetter H. Functional cardiac assessment before and after left ventricular anterior aneurysm repair, especially related to work capacity. Cardiology. 1988;75:10816.

5. Dymond DS, Stephens JD, Stone DL, Elliot AT, Rees CM, Spurrell RAJ. Combined exercise, radionuclide and hemodynamic evaluation of left ventricular aneurysmectomy. Am Heart J. 1982;104:977-87. 
6. Jatene AD. Left ventricular aneurysmectomy: resection or reconstruction. J Thorac Cardiovasc Surg. 1985;89:321-31.

7. Dor V, Saab M, Coste P, Lornaszeweska M, Montiglio F. Left ventricular aneurysm: a new surgical approach. J Thorac Cardiovasc Surg. 1989;37:11-9.

8. Sinatra R, Macrina F, Braccio M, Melina G, Luzi G, Ruvulo G, et al. Left ventricular aneurysmectomy; comparison between two techniques: early and late results. Eur J Cardiothorac Surg. 1997;12: 291-7.

9. Di Donato M, Sabatier M, Montiglio F, Maioli M, Toso A, Fantini F, et al. Outcome of left ventricular aneurysmectomy with patch repair in patients with severely depressed pump function. Am J Cardiol. 1995; 76:557-61.

10. Athanasuleas CL, Stanley AWH, Buckberg GD, Dor V, Di Donato M, Blackstone EH, et al. Surgical anterior ventricular endocardial restoration (SAVER) in the dilated remodeled ventricle after anterior myocardial infarction. J Am Coll Cardiol. 2001;37:1199-209.

11. Di Donato M, Sabatier M, Dor V, Gensini GF, Tosa A, Maioli M, et al. Effects of the Dor procedure on left ventricular dimension and shape and geometric correlates of mitral regurgitation one year after surgery. J Thorac Cardiovasc Surg. 2001;121:91-6.

12. Schreuder JJ, Van der Veen FH, Van der Velde ET, Delahaye F, Alfieri $\mathrm{O}$, Jegaden $\mathrm{O}$, et al. Left ventricular pressure-volume relationships before and after cardiomyoplasty in patients with heart failure. Circulation. 1997;96:2978-86.

13. Schreuder JJ, Steendijk P, Van der Veen FH, Alfieri O, Van der Nagel $\mathrm{T}$, Lorusso R, et al. Acute and short-term effects of partial left ventriculectomy in dilated cardiomyopathy: assessment by pressurevolume loops. J Am Coll Cardiol. 2000;36:2104-14.

14. Baan J, van der Velde ET, De Bruin HG, Smeenk GJ, Koops J, Van Dijk AD, et al. Continuous measurement of left ventricular volume in animals and humans by conductance catheter. Circulation. 1984;70: $812-23$.

15. Schreuder JJ, Biervliet JD, van der Velde ET, Ten Have K, Van Dijk AD, Meijne NG, et al. Systolic and diastolic pressure volume relationships during cardiac surgery. J Cardiothorac Vasc Anesth. 1991;5:53945 .
16. Steendijk P, Van der Velde ET, Baan J. Left ventricular stroke volume by single and dual excitation of the conductance catheter in dogs. Am J Physiol Heart Circ Physiol. 1993;264:H2198-207.

17. Van der Velde ET, Van Dijk AD, Steendijk P, Diethelm L, Chagas T, Lipton MJ, et al. Left ventricular segmental volume by conductance catheter and cine-CT. Eur Heart J. 1992;13(suppl E):15-21.

18. Steendijk P, Tulner SA, Schreuder JJ, Bax JJ, Van Erven L, Van Der Wall EE, et al. Quantification of left ventricular mechanical dyssynchrony by conductance catheter in heart failure patients. Am J Physiol Heart Circ Physiol. 2004;286:H723-30.

19. Mirsky I. Assessment of diastolic function: suggested methods and future considerations. Circulation. 1984;69:836-41.

20. Suga H, Yamada O, Goto Y. Energetics of ventricular contraction as traced in the pressure-volume diagram. Fed Proc. 1984;43:2411-3.

21. Grossi EA, Chinitz LA, Galloway AC, Deliandes J, Schwartz DS, McLoughlin DE, et al. Endoventricular remodeling of left ventricular aneurysm. Functional, clinical and electrophysiological results. Circulation. 1995;92(suppl II):98-100.

22. Hayashida W, Kumada T, Kohno F, Noda M, Ishikawa N, Kambayashi M, et al. Left ventricular relaxation in dilated cardiomyopathy: relation to loading conditions and regional nonuniformity. J Am Coll Cardiol. 1992;20:1082-91.

23. Di Donato M, Sabatier M, Dor V, Toso A, Maioli M, Fantini F. Akinetic versus dyskinetic postinfarction scar: relation to surgical outcome in patients undergoing endoventricular circular patch plasty repair. J Am Coll Cardiol. 1997;29:1569-75.

24. Ratcliffe MB, Wallace AW, Salahieh A, Hong J, Ruch S, Hall TS. Ventricular volume, chamber stiffness, and function after anteroapical aneurysm plication in the sheep. J Thorac Cardiovasc Surg. 2000;119: $115-24$.

25. Maughan WL, Sunawaga K, Burkhoff D, Graves WL, Hunter WC, Sagawa K. Effects of heart rate on the canine end-systolic pressurevolume relationship. Circulation. 1985;72:654-9.

26. Suga H, Sagawa K, Shoukas AA. Load independence of the instantaneous pressure-volume ratio of the canine left ventricle and effects of epinephrine and heart rate on the ratio. Circ Res. 1973;32:314-22. 